\title{
60 ans après le Deuxième Congrès des Écrivains et Artistes Noirs (Rome, 1959): l'héritage, dir. B. MOURALIS, N. RASCHI
}

\section{Emanuela Cacchioli}

\section{OpenEdition}

\section{Journals}

Édition électronique

URL : https://journals.openedition.org/studifrancesi/44388

DOI : 10.4000/studifrancesi.44388

ISSN : 2427-5856

Éditeur

Rosenberg \& Sellier

\section{Édition imprimée}

Date de publication : 1 juin 2021

Pagination : 251-252

ISSN : 0039-2944

\section{Référence électronique}

Emanuela Cacchioli, «60 ans après le Deuxième Congrès des Écrivains et Artistes Noirs (Rome, 1959):

I'héritage, dir. B. mouralıs, N. RASCHI », Studi Francesi [En ligne], 193 (LXV | I) | 2021, mis en ligne le 01 juillet 2021, consulté le 15 octobre 2022. URL : http://journals.openedition.org/studifrancesi/44388 ; DOI : https://doi.org/10.4000/studifrancesi.44388

Ce document a été généré automatiquement le 15 octobre 2022

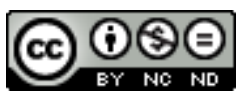

Creative Commons - Attribution - Pas d'Utilisation Commerciale - Pas de Modification 4.0 International - CC BY-NC-ND 4.0

https://creativecommons.org/licenses/by-nc-nd/4.0/ 


\title{
60 ans après le Deuxième Congrès des Écrivains et Artistes Noirs (Rome, 1959): l'héritage, dir. B. MOURALIS, N. RASCHI
}

\author{
Emanuela Cacchioli
}

\section{RÉFÉRENCE}

60 ans après le Deuxième Congrès des Écrivains et Artistes Noirs (Rome, 1959): l'héritage, dir. B. MOURALIS, N. RASCHI, «Francofonia» 77, autunno 2019, 176 pp.

1 Soixante ans après le Deuxième Congrès des écrivains et des Artistes Noirs qui a eu lieu à Rome en 1959, la revue "Francofonia" consacre un dossier à cet événement et aux répercussions que ce dernier a eues dans le temps et dans l'espace. Bernard Mouralis et Nataša Raschi nous proposent un ensemble d'articles dans une optique multidisciplinaire afin d'aborder quelques réflexions encore peu explorées par la critique. Le congrès de Rome a été une étape fondamentale de la prise de conscience de l'identité noire qui suit la conférence de Bandoeng de 1955 et le premier Congrès de Paris de 1956. Un parcours qui a comme but ultime la nécessité d'une indépendance politique, mais qui passe par l'affirmation d'une identité noire. Notamment l'assemblée de Rome met l'accent sur la notion d'unité des cultures négro-africaines et de leur apport à la civilisation universelle. Selon les intervenants, l'avenir du monde entier passe par l'émancipation de l'Afrique qui a le pouvoir de renouveler l'imaginaire collectif grâce à une relecture du passé et à une ouverture sur l'avenir. Les intellectuels réunis en Italie ont mis en relief l'héritage des valeurs culturelles et leur contribution à l'humanisme; ils ont célébré le solidarisme et le particularisme noir dans le contexte de la Négritude; ils ont proposé de nouvelles pistes pour la refondation du paradigme africain. Si d'un côté les chercheurs se rappellent de ce Congrès pour son projet politique - c'est une étape concrète dans le chemin conduisant à l'indépendance des nombreux états africains dans les années soixante -, de l'autre côté, les assemblées 
successives ont été moins efficaces et ont perdu l'esprit novateur de Rome. Même la critique semble avoir dévalorisé la portée de la dimension politique et éthique du Congrès de Rome. Cette attitude est la conséquence du changement de perception de l'histoire: à la phase de l'optimisme qui accompagne l'espoir pour l'indépendance politique suit une époque de désillusion car la fin de la domination correspond à un moment chaotique et à une libération partiellement inaccomplie d'un point de vue culturel. Les littératures francophones contemporaines entretiennent un rapport ambivalent avec le pouvoir qui relève de la contradiction: d'un côté Paris reste indiscutablement le centre culturel, mais dans un rapport de tension avec l'héritage local qui est repris et remis en question. Le résultat est souvent un ouvrage hybride qui se construit autour de la déconstruction du langage et d'un travail de réécriture en mesure de produire un renouveau littéraire. Afin de saisir les spécificités du Congrès de Rome et ses retombées historiques et culturelles, Bernard Mouralis et Nataša Raschi ont réuni plusieurs contributions qui, à partir de l'analyse des actes de l'assemblée, nous offrent une première lecture critique de cet événement et de ses implications spatiotemporelles, culturelles et pragmatiques.

2 Dans le premier article, (pp.13-28) Jean DERIVE nous offre un aperçu des trois périodes que traversent les productions romanesques francophones en Afrique et pour chaque époque il en trace les liens avec le Congrès de Rome. Le premier moment s'étale de 1950 à 1970 et reprend l'un des pivots des interventions de 1959: les romanciers se focalisent sur leur participation à la culture universelle, revendiquent une place en tant que sujets, en tant qu'artistes et critiquent l'attitude négationniste de l'Occident. La deuxième phase est liée à la génération de la désillusion qui a pris conscience des répercussions négatives des nouveaux régimes locaux. De 1970 à 2000 nous assistons à une prise de distance par rapport à l'académisme français afin d'aboutir à une poétique originale à même de représenter l'identité africaine et la perception personnelle. La troisième période peut être cadrée entre 2000 et 2018 et met définitivement en crise l'idée d'unité qui était le pivot du Congrès de Rome: plutôt que parler de «roman africain", nous assistons à une multiplication des perspectives, à une déterritorialisation qui s'impose pour les écrivains migrants, à une écriture métissée et à une veine douce-amère qui conjugue l'ironie et la cruauté de la condition humaine. La contribution de Sélom Komlan GBANOU (pp. 29-48) porte sur un aperçu historique concernant les revendications identitaires des Noirs, dont le Congrès de Rome constitue le centre. Le moment de départ de cette quête de solidarité dans la diaspora est à retrouver aux États-Unis, à Harlem, alors qu'après 1959, nous assistons à une prolifération de projets qui se basent sur le lien entre pouvoir et savoir. La réflexion se penche donc sur les lieux de production (et les différences entre Nord et Sud, centre et marges), de discussion (c'est-à-dire les pays où l'on organise des colloques et des conférences) et de jugement (les discours critiques et l'importance des prix décernés). La nécessité de décentraliser les lieux de pouvoir/savoir et de combiner plusieurs étapes géo-culturelles s'impose de plus en plus dans la société contemporaine. L'article de Josias SEMUJANGA (pp. 49-72) se focalise sur l'actualité des questions débattues à Rome en 1959. Les problèmes économiques, ainsi que les revendications politiques et culturelles n'ont pas changé et l'histoire de la critique littéraire africaine est encore liée aux idées sorties des discussions du Congrès. Pour ce faire, le chercheur questionne notamment trois aspects: l'esthétique de l'hybridité, la nécessité d'une langue d'écriture contaminée et en mesure de saisir des interférences multiples et l'engagement de l'écrivain qui s'interroge sur la société à laquelle il appartient. Odile 
CAZENAVE (pp. 73-88) questionne la figure du père dans les romans africains des vingt dernières années. L'article dépasse les thématiques de la paternité, de la filiation et de la relation intergénérationnelle pour aboutir à une réflexion sur l'héritage et sur les pères culturels qui ont participé au Congrès de Rome. Le résultat est un roman qui s'enrichit des apports mémoriels provenant de Césaire, Diop, Senghor et Fanon et qui ne se limite plus à une figuration d'un moment historique unique. Florian ALIX (pp. 89-104) examine la relation entre culture et politique à partir des discours prononcés en 1959. Les intellectuels se sont interrogés à propos du rôle du leader politique et de son rapport avec la culture. Deux perspectives sont possibles: le dirigeant politique peut être une émanation de la culture qu'il utilise comme instrument de son action ou bien c'est l'homme de culture qui devient leader. Le lien entre les deux pôles est donc un sujet central de l'écriture romanesque, mais la connexion se dévalorise quand le dirigeant politique se transforme en dictateur: la formation culturelle ne vise plus le bien-être du peuple, mais des intérêts personnels. La contribution de Nataša RASCHI (pp. 105-125) part du constat que les femmes sont absentes au Congrès de Rome. L'article se propose d'interpréter ce «vide» au niveau diachronique et synchronique et d'en dresser un bilan des causes et des conséquences. Absentes du point de vue physique, ce sont les hommes qui sont leur porte-parole. Pour trouver des femmes qui se consacrent à l'activité littéraire et au discours critique, il faudra attendre les années quatre-vingts. Comme d'habitude, la revue s'enrichit de plusieurs comptes rendus et de notes de lecture qui offrent un panorama des dernières publications dans le domaine de la francophonie.

3 La revue "Francofonia" nous offre un dossier riche qui retrace quelques pistes de recherche à partir d'un événement majeur de l'affirmation de l'identité noire. Avec une perspective multidisciplinaire, l'ensemble des contributions amorce l'analyse des actes du Congrès de Rome et nous propose des réflexions à propos de l'héritage des positions tenues et des répercussions dans les ouvrages littéraires postérieurs en Afrique subsaharienne et dans la diaspora. Il s'agit d'une première approche qui mérite d'autres approfondissements et une ultérieure systématisation, mais les éléments principaux ont déjà été touchés et développés avec des articles pertinents et efficaces pour réfléchir sur les enjeux de la mondialisation. 